Doi: HTTPS://DOI.ORG/10.23910/2/2021.0434

\title{
Isolation and Screening of Lignocellulolytic Microorganisms from Different Locations of Dang (Gujarat) India
}

\author{
R. P. Bambharolia ${ }^{1 *}$, Trupti K. Vyas ${ }^{2}$ and A. J. Deshmukh ${ }^{1}$ \\ ${ }^{1}$ College of Agriculture, Navsari Agricultural University, Waghai, Gujarat (394 730), India \\ ${ }^{2}$ Food Quality Testing Laboratory, Navsari Agricultural University, Navsari, Gujarat (396 450), India
}

\section{Corresponding Author}

R. P. Bambharolia

e-mail: rpbmicro@gmail.com

\author{
Article History \\ Article ID: IJEP0434 \\ Received on $16^{\text {th }}$ July, 2021 \\ Received in revised form on $26^{\text {th }}$ October, 2021 \\ Accepted in final form on $20^{\text {th }}$ November, 2021
}

\section{Abstract}

Total 56 (CD1 to CD56) bacteria and 43 (LD1 to LD43) fungi were isolated from different collected samples from District Dang, Gujarat (India). Subsequently, it was screened for cellulose and lignin degrading capabilities. Out of total 56 bacterial isolates, 41 showed clear zones around the colonies on CMC agar and only four isolates showed color zone around the colonies on ABTS agar. Among 43 fungal isolates, 40 showed clear zones around the colonies on CMC agar and 26 isolates showed color zone around the colonies on ABTS agar. Among the isolates, bacterial isolates CD11, CD17, CD19, CD22 and CD35 showed higher zone to colony ratio on CMC agar and fungal isolates LD1, LD4, LD5, LD9, LD15, LD19, LD20 and LD39 showed higher color change on ABTS agar which were selected for further screening.

Keywords: ABTS agar, cellulose, CMC agar, lignin

\section{Introduction}

Lignocellulose is the chief component of biomass comprising forestry, agricultural and agro-industrial wastes and causes environmental pollution. It is an abundant, renewable organic material as well as inexpensive energy source, which is accumulated every year around $60 \%$ of the plant matter produced by photosynthesis activity (also called photo biomass) (Kuhad et al., 1997). Lignocellulosic waste grouped into different categories such as agricultural residues (viz. straw, stover, peelings, cobs, stalks, nutshells, non-food seeds, biogases), wood residues (sawdust and paper mill discards), grasses, waste paper, domestic wastes (lignocellulose garbage and sewage), food industry residues and municipal solid wastes.

Lignocellulosic wastes are referred to as discard of plant biomass and consist of three major components viz. cellulose, hemicellulose and lignin (Deobald and Crawford, 1997). In addition, low amounts of other materials such as ash, proteins and pectin are also found in lignocellulosic residues, depending on the source of origin of waste (Sanchez, 2009). Cellulose is the dominant structural polysaccharide of plant cell walls (35 to 50\%), followed by hemicellulose (20 to 35\%) and lignin (10 to 25\%) (Saha, 2003).

Cellulose and lignin-degrading microorganisms accelerate the biodegradation of crop residues such as straw, leaves, trash, etc. (Gaur, 1999). The period of decomposition can be reduced by the use of efficient lignocellulolytic microorganisms. Cellulolytic microbes can convert the cellulose into soluble sugars by enzymatic hydrolysis. Similarly, ligninolytic microbes produce laccase, lignin peroxidase and manganese peroxidase enzymes which will also reduce the complex compounds into simpler ones.

Turpeinen et al. (2003) screened different phases of compost consisting of municipal wastes, paper and wood chips for isolation of lignin degrading microorganisms using medium containing multiple antibiotics and they observed that only two isolates of Paecilomyces inflatus isolated from the cooling and maturing phases of composting formed characteristic dark green rings around the fungal mycelium on ABTS-agar medium which indicated the production of extracellular oxidoreductases, i.e. laccases and/or peroxidases. Balamurugan et al. (2011) reported that total 25 bacteria showed zone of clearance around the colonies on MSM agar plates containing $0.1 \%$ cellulose. About $58 \%$ of the total fungi isolated were found to be potential lignin degraders as it showed very clear zones on low nitrogen media Geethanjali (2012).

Madhavan et al. (2017) reported that out of 103 different bacteria isolated from different samples, 51 bacterial isolates showed zone of clearance on carboxymethylcellulose (CMC) agar plates by producing cellulase enzyme and 10 isolates 
showed positive result on ABTS agar plates by producing Lignin Modifying Enzymes (LME). Total 28 microorganisms were isolated from degraded wood, degraded leaves, compost and termite gut through enrichment of the sample. 20 bacterial colonies and 8 fungal colonies were isolated, from those isolates only 2 bacterial and 2 fungal isolates confirmed as cellulose and lignin degraders through conformational test (Keerthana et al., 2019). Among all the tested isolates, 3 strains formed a dark green halo in ABTS supplemented plates, while 2 strains formed orange halo in 2,6-DMP supplemented plates (Binkowska et al., 2020). Maravi and Kumar (2020) screened 14 bacterial isolates for cellulase enzyme production on CMC agar and observed that the size of zone of clearance around the colonies on $\mathrm{CMC}$ agar after staining with congo red dye ranged from $2.1 \mathrm{~mm}$ to $30 \mathrm{~mm}$. Whereas, hydrolytic capacity of these isolates varied from 5 to 29 .

\section{Materials and Methods}

\subsection{Isolation of lignocellulolytic microorganisms}

\subsubsection{Collection of samples}

Samples were collected for the isolation of lignocellulolytic microorganisms from city wastes (Rajendrapur village), forest soil (Waghai), forest litter (Waghai), forest degraded wood (Waghai), forest degraded wood (Subir), farmyard manure (Rajendrapur Farm), farmyard manure (Cafeteria, CoA, Waghai), decomposed manures (Bhavandagad village) and rural compost (Waghai). Approximately $20 \mathrm{~g}$ of the sample were collected in the sterile polythene bag and taken into the laboratory for further analysis.

\subsubsection{Isolation of cellulolytic microorganisms}

Cellulose degrading microbes were isolated by the enrichment method. For enrichment, 1.0g of each collected sample was added separately in minerals salts medium (MSM) broth containing $0.1 \%$ of Carboxyl Methyl Cellulose (CMC) and incubated at $30^{\circ} \mathrm{C}$ and $100 \mathrm{rpm}$ for two days under the shaking condition. From this stock, $10 \mathrm{ml}$ of the sample was taken and transferred to fresh MSM broth containing $0.1 \%$ $\mathrm{CMC}$ substrate as a carbon source. After overnight incubation at $30^{\circ} \mathrm{C}$, a $1.0 \mathrm{ml}$ of sample were serially diluted up to $10^{6}$, and then the $10^{4}, 10^{5}$ and $10^{6}$ dilutions were plated onto the CMC agar ( $\mathrm{gl}^{-1}$ of CMC 10.0; Peptone, 10.0; $\mathrm{K}_{2} \mathrm{HPO}_{4}, 2.0$; $\mathrm{MgSO}_{4} .7 \mathrm{H}_{2} \mathrm{O}, 0.3$; $\left(\mathrm{NH}_{4}\right)_{2} \mathrm{SO}_{4}, 2.5$; Gelatin, 2.0; Agar, 15.0 and $\mathrm{pH}$ adjusted to 7). Plates were incubated at $30 \circ \mathrm{C}$ and examined periodically for clear zone around the colonies. Colonies that showed a zone of clearance were purified by repeated streaking. The purified colonies were preserved at $4^{\circ} \mathrm{C}$ on nutrient agar (NA) for further studies.

\subsubsection{Isolation of ligninolytic microorganisms}

Lignin degrading microbes were isolated by the enrichment method. For enrichment $1.0 \mathrm{~g}$ of each collected sample was added separately in MSM broth containing $1.0 \%$ of wheat straw as the sole carbon source and incubated at $26^{\circ} \mathrm{C}$ for
20 days under the shaking condition. From this $1.0 \mathrm{ml}$ of sample were serially diluted up to $10^{6}$, and then the $10^{4}, 10^{5}$ and $10^{6}$ dilutions were plated onto the Lignin Basal Medium (LBM) (Archibald, 1992) (g l-1 of $\mathrm{KH}_{2} \mathrm{PO}_{4}, 1.0 ; \mathrm{C}_{4} \mathrm{H}_{12} \mathrm{~N}_{2} \mathrm{O}_{6}, 0.5$; $\mathrm{MgSO}_{4} .7 \mathrm{H}_{2} \mathrm{O}, 0.5 ; \mathrm{CaCl}_{2} .2 \mathrm{H}_{2} \mathrm{O}, 0.01$; Yeast Extract, 0.01 ; $\mathrm{CuSO}_{4} . \mathrm{H}_{2} \mathrm{O}, 0.001 ; \mathrm{Fe}_{2}\left(\mathrm{SO}_{4}\right)_{3}, 0.001 ; \mathrm{MnSO}_{4} . \mathrm{H}_{2} \mathrm{O}, 0.001$; Agar, 16.0) supplemented with $0.1 \% \mathrm{w} / \mathrm{v}$ ABTS (2,2- Azinobis (3-ethylbenz-thiazoline-6-sulfonic acid)) and separately sterilized $1 \mathrm{ml}$ of $20 \% \mathrm{w} / \mathrm{v}$ aqueous glucose for each $100 \mathrm{ml}$ of growth medium. Plates were incubated at $26^{\circ} \mathrm{C}$ and examined periodically for the formation of a green color zone around colonies. Colonies that showed green color were purified by repeated streaking. The purified colonies were preserved at $4^{\circ} \mathrm{C}$ on NA for further studies.

\subsection{Screening of efficient lignocellulolytic microorganisms}

\subsubsection{Screening of cellulolytic microorganisms}

Isolated microbes were screened for cellulolytic activity as per standard procedure given by Andro et al. (1984). Isolated bacteria were spot inoculated in to CMC agar and incubated at $35 \pm 2^{\circ} \mathrm{C}$ for $48 \mathrm{hrs}$ in the incubator and for fungus isolates $5 \mathrm{~mm}$ disc of 5 days old mycelium of each fungal strain was placed on $\mathrm{CMC}$ agar and incubated at $26 \pm 2^{\circ} \mathrm{C}$ for 5 days. After incubation plates were flooded with $0.1 \%$ Congo red solution for 10-12 min then washed with $1 \mathrm{M} \mathrm{NaCl}$. After staining clear zone appeared around microbial colonies indicating cellulose hydrolysis and the zone to colony ratio was calculated and recorded using the formula as follows.

Zone to colony ratio=(Diameter of zone $(\mathrm{mm})) /($ Diameter of bacterial colony $(\mathrm{mm})$ )

\subsubsection{Screening of ligninolytic microorganisms}

Primary screening for the ligninolytic activity of isolated microbes was performed by spot inoculation. Isolated bacteria were spot inoculated in to ABTS agar medium (LBM supplemented with $0.1 \% \mathrm{w} / \mathrm{v}$ ABTS and $1 \mathrm{ml}$ of $20 \% \mathrm{w} / \mathrm{v}$ aqueous glucose (separately sterilized) for each $100 \mathrm{ml}$ of growth medium) (Archibald, 1992) and incubated at $35 \pm 2{ }^{\circ} \mathrm{C}$ for $48 \mathrm{hrs}$ in the incubator and for fungus isolates $5 \mathrm{~mm}$ disc of 5 days old mycelium of each fungal strain was placed on ABTS agar and incubated at $26 \pm 2^{\circ} \mathrm{C}$ for 5 days. The colorless agar medium turns green due to the oxidation of ABTS to ABTS-azine if isolates produced laccase enzyme (Niku-Paavola et al., 1990). Incubated plates were observed each day, for the growth as well as for the appearance of color zones around the colonies.

\section{Results and Discussion}

Total 56 bacteria and 43 fungi were isolated and purified on nutrient agar and potato dextrose agar, respectively by enrichment method (Table 1). Isolates were further screened for their lignocellulosic activity. Similarly, El-Hanafy et al. (2007), Balamurugan et al. (2011) and Sharma et al. (2017) were used enrichment method for the isolation of 


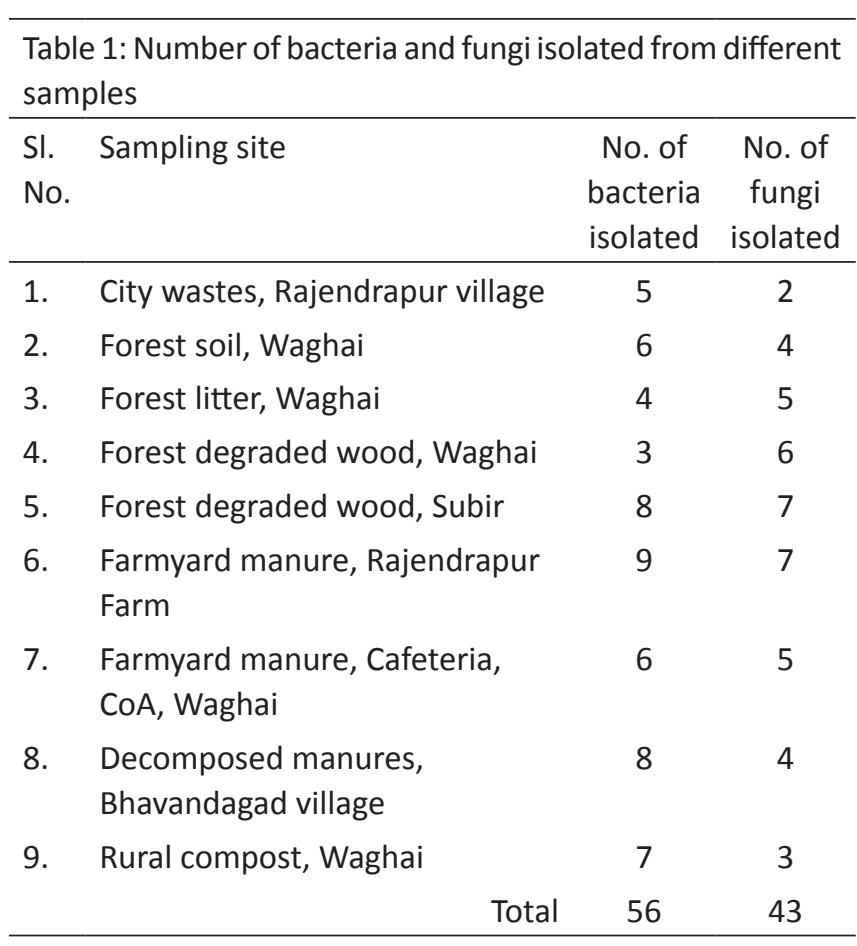

lignocellulolytic microorganisms from different samples.

Total 56 (CD1 to CD56) bacterial and 43 (LD1 to LD43) fungal isolates were obtained from collected samples and were screened for cellulolytic and ligninolytic activity on CMC and ABTS agar, respectively. Microorganisms with cellulolytic activity produced clear zone around the colonies on CMC agar after staining with Congo red dye and appearance of green color around the colonies on ABTS agar considered as positive for ligninolytic activities. Out of total 56 bacterial isolates, 41 showed clear zones around the colonies on CMC agar and only four isolates showed color zone around the colonies on ABTS agar (Table 2 and Figure 1). Out of total 43 fungal isolates, 40 showed clear zones around the colonies on CMC agar and 26 isolates showed color zone around the colonies on ABTS agar (Table 3 and Figure 1). Likewise, Rathore et al. (2014) and Saini et al. (2012) used CMC agar and congored dye for primary screening of the cellulolytic microorganisms and Binkowska et al. (2020) used ABTS supplemented plates

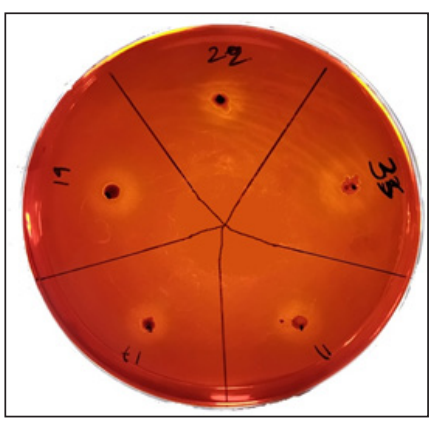

A. CMC agar

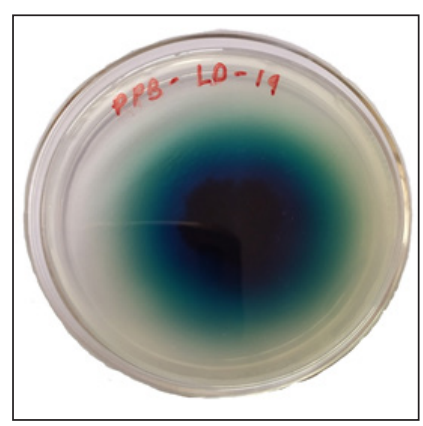

B. ABTS agar
Figure 1: A. Zone of cellulose degrading isolates on $C M C$ agar, $B$. Color change of lignin degrading isolate on ABTS agar for primary screening of laccase producing microorganisms. Among the isolates, bacterial isolates CD35, CD19 and CD22

Table 2: Screening of bacterial isolates on CMC and ABTS agar SI. Sampling No. of Code of Zone to Result No. site bacteria bacterial colony on ABTS isolated isolates ratio on agar CMC agar

\begin{tabular}{llllll}
\hline 1. & City & 5 & CD1 & 1.33 &
\end{tabular}

2. wastes,

2. Rajendra-

3. pur village

4.

$\mathrm{CD} 2$

$\mathrm{CD} 3 \quad 1.81$

5.

CD4

1.50

CD5

1.39

6. Forest soil, 6

7. Waghai

CD6

1.58

8.

CD7

CD8

9.

CD9

10.

CD10

11.

CD11 2.01

12. Forest

13. litter,

14.

Waghai

4

$\mathrm{CD} 12$

1.60

CD13

1.75

CD14

15.

CD15

1.61

16. Forest

17. degraded wood,

18. Waghai

3

CD16

1.84

CD17

1.91

CD18

1.41

19. Forest

20. degraded wood,

21. Subir

22.

23.

24.

25.

26.

27. Farmyard

28. manure,

29. Rajendra-

29. pur Farm

CD19

2.72

CD20

1.43

$\mathrm{CD} 21$

1.36

$\mathrm{CD} 22$

2.47

$\mathrm{CD} 23$

1.79

CD24

1.65

CD25

CD26

9

CD27

1.58

CD28

CD29

1.56

CD30

CD31

1.57

CD32

1.60

CD33

CD34

1.48

CD35

3.02

Table 2: Continue... 


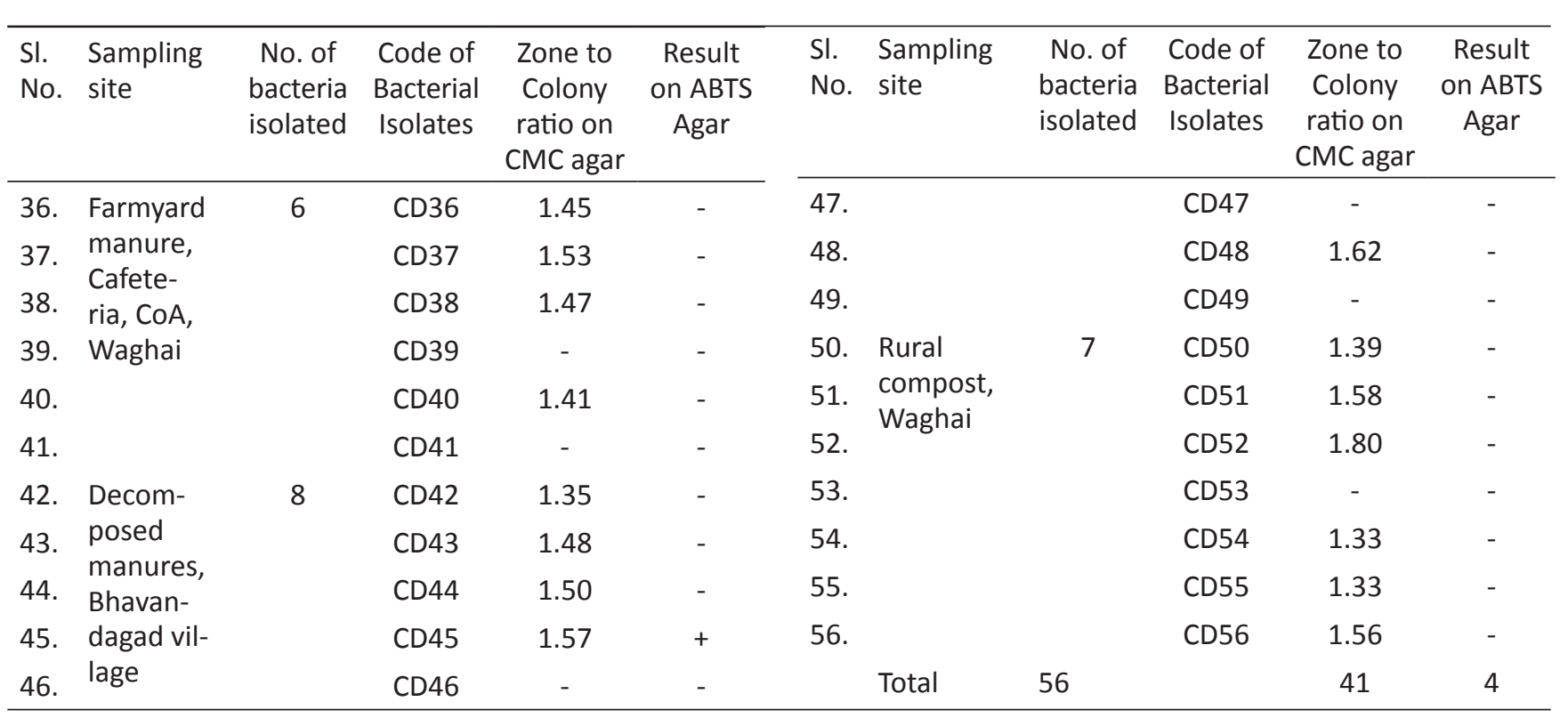

Table 3: Screening of fungal isolates on CMC and ABTS agar

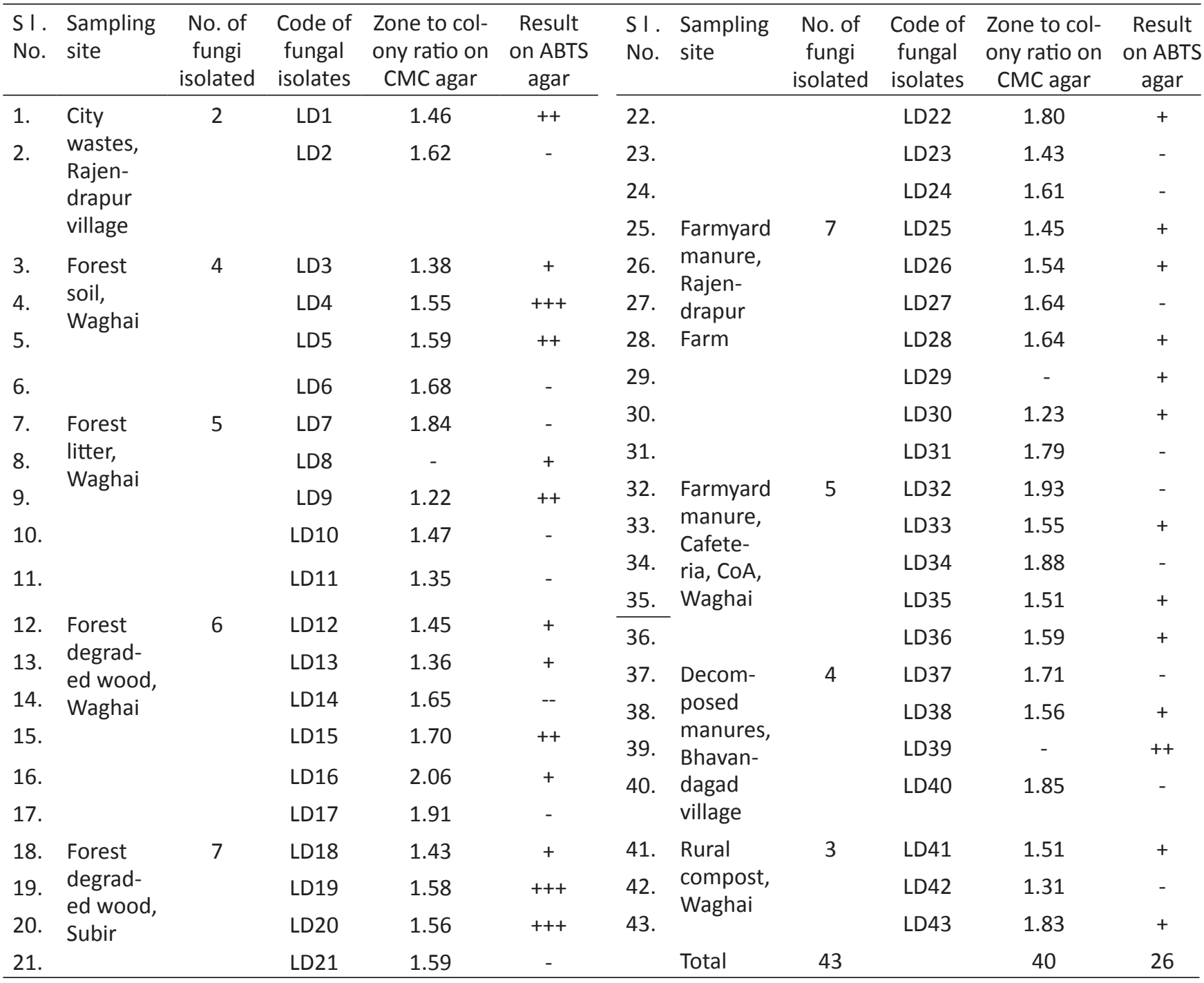


produced higher zone to colony ratio on CMC agar i.e. 3.02, 2.72 and 2.47, respectively and fungal isolates (LD1, LD4, LD5, LD9, LD15, LD19, LD20 and LD39) showed visually higher color change on ABTS agar. From the primary screening, bacterial isolates CD11, CD17, CD19, CD22 and CD35 and fungal isolates LD1, LD4, LD5, LD9, LD15, LD19, LD20 and LD39 were selected for further study.

\section{Conclusion}

Out of 56 bacteria and 43 fungi isolated, 41 bacterial and 40 fungal isolates showed clear zones around the colonies on CMC agar and only four bacterial and 26 fungal isolates showed color zone around the colonies on ABTS agar.

\section{References}

Andro, T., Chambost, J.P., Kotoujansky, A., Cattano, J., Barras, F., 1984. Mutants of Erwinia chrysanthemi defective in secretion of pectinase and cellulase. Journal of Bacteriology 160, 1199-1203.

Archibald, F.S., 1992. A new assay for lignin-type peroxidases employing the dye azure B. Applied and Environmental Microbiology 58, 3110-3116.

Balamurugan, A., Jayanthi, R., Nepolean, P., Pallavi, R.V., Premkumar, R., 2011. Studies on cellulose degrading bacteria in tea garden soils. African Journal of Plant Science 5, 22-27.

Binkowska, A.G., Jasinska, A., Długonski, A., Plocinski, P., Dlugonski, J., 2020. Laccase activity of the ascomycete fungus Nectriella pironii and innovative strategies for its production on leaf litter of an urban park. PLOS ONE 15, 1-18.

Deobald, L.A., Crawford, D.L., 1997. Lignocellulose biodegradation. In: Hurst, C.J., Knudsen, G.R., Stetzenbach, L.D., Walter, M.V. (Eds). Manual of Environmental Microbiology 10, 730-737.

El-Hanafy, A.A., Abd-Elsalam, H.E., Hafez, E.E., 2007. Fingerprinting for the lignin degrading bacteria from the soil. Journal of Applied Sciences Research 3, 470-475.

Gaur, A.C., 1999. Microbial technology for composting of agricultural residues by improved methods. Indian Council of Agricultural Research New Delhi, 34-36.

Geethanjali, P.A., 2012. A study on lignin degrading fungi isolated from the litter of evergreen forests of Kodagu (D), Karnataka. International Journal of Environmental Sciences 2, 2034-2039.
Keerthana, S., Kalaiselvi, P., Maheshwari, M., Kalaiselvi, T., 2019. Isolation and screening of lignin and cellulose degrading proficient microbial strains from diverse biotic substrates based on qualitative traits. International Journal of Current Microbiology and Applied Sciences 8, 475-483.

Kuhad, R.C., Singh, A., Ericsson, K.E., 1997. Microorganisms and enzymes involved in the degradation of plant fiber cell walls. Advances in Biochemical Engineering/ Biotechnology 57, 45-125.

Madhavan, N.T., Patel, K.G., Vyas, T.K., Ganesh, S., 2017. Exploring microbes for their cellulolytic and lignolytic enzyme activity for manure preparation. International Journal of Current Microbiology and Applied Sciences 6, 3808-3816.

Maravi, P., Kumar, A., 2020. Isolation, screening and identification of cellulolytic bacteria from soil. Biotechnology Journal International 24, 1-8.

Niku-Paavola, M.L., Raaska, L., Itavaara, M., 1990. Detection of white-rot fungi by a nontoxic stain. Mycological Research 94, 27-31.

Rathore, S.S., Mannivannan, A., Narendhirakannan, R.T., 2014. Screening of cellulase producing microorganisms from lake area containing water hyacinth for enzymatic hydrolysis of cellulose. Journal of Advanced Scientific Research 5, 23-30.

Saha, B.C., 2003. Hemicellulose bioconversion. Journal of Industrial Microbiology and Biotechnology 30, 279-291.

Saini, J.K., Arti, Tewari, L., 2012. Simultaneous isolation and screening of cellulolytic bacteria: selection of efficient medium. Journal of Pure and Applied Microbiology 6, 1339-1344.

Sanchez, C., 2009. Lignocellulosic residues: biodegradation and bioconversion by fungi. Biotechnology Advances 27, 185-194.

Sharma, A., Aggarwal, N.K., Yadav, A., 2017. Isolation and screening of lignolytic fungi from various ecological niches. Universal Journal of Microbiology Research 5, 25-34.

Turpeinen, B.K., Tuomela, M., Hatakka, A., Hofrichter, M., 2003. Lignin degradation in a compost environment by the deuteromycete Paecilomyces inflatus. Applied Microbiology and Biotechnology 61, 374-379. 